\title{
Visceral Branches of the Abdominal Aorta in the New Zealand Rabbit: Ten Different Patterns
}

\author{
Ramas Viscerales de la Aorta Abdominal en el Conejo Neozelandés: \\ Diez Patrones de Presentación
}

\begin{abstract}
Jorge Arredondo ${ }^{1}$; Roberto Saucedo ${ }^{1}$; Sergio Recillas ${ }^{2}$; Victor Fajardo ${ }^{3}$; Octavio Castelán ${ }^{1}$; Manuel González-Ronquillo ${ }^{1}$ \& Wendy Hernández ${ }^{1}$
\end{abstract}

ARREDONDO, J.; SAUCEDO, R.; RECILlAS, S.; FAJARDO, V.; CASTELÁN, O.; GONZÁLEZ-RONQUILLO, M. \& HERNÁNDEZ, W. Ramas viscerales de la aorta abdominal en el conejo neozelandés: Diez patrones de presentación. Int. J. Morphol., 35(1):306-309, 2017.

SUMMARY: The abdominal aorta of the rabbit has been in the focus of research to develop new platforms of training diagnostic and therapeutic protocols; and for testing endovascular devices and materials, however, few descriptions of the anatomy of the abdominal aorta and its emerging visceral branches has been reported on the scientific literature for this specie. Anatomical variations are common and should have in mind during research and clinical trials. The aim of this study was to describe the different patterns that can occur in the visceral branches arising from the abdominal aorta in the rabbit.

KEY WORDS: Aorta; Vascular injection; Rabbit; Anatomical variation.

\section{INTRODUCTION}

The abdominal aorta of the rabbit has been in the focus of research to develop new platforms of training diagnostic and therapeutic protocols (Li et al., 2016); and for testing endovascular devices and materials (Simgen et al., 2016; Zhu et al., 2015) due to its capability for mimicking human aortic aneurysm disease (Fan et al., 2015; Yoo et al., 2015). However, few descriptions of the anatomy of the abdominal aorta and its emerging visceral branches has been reported on the scientific literature for this specie (Nowicki et al., 2010). Classical description of the visceral branches emerging from the abdominal aorta have been reported emerging from cranial to caudal as it follows: 1) Celiac trunk, 2) cranial mesenteric artery, 3) right renal artery, 4) left renal artery, 5) right gonadal artery, 6) left gonadal artery and 7) caudal mesenteric artery (Getty et al., 1982; König \& Liebich, 2009; Nowicki et al.; Dyce et al., 2012). The aim of this study was to describe the different patterns that can occur in the visceral branches arising from the abdominal aorta in the rabbit.

\section{MATERIAL AND METHOD}

Animals. The project was approved by the Animal Care and Ethics Committee of the Faculty of Veterinary Medicine and Animal Husbandry of the Autonomous University of the State of Mexico. Thirty male New Zealand rabbits [average age 6 months (range: 5-7), mean weight $1.1 \mathrm{~kg}$ (range: $1.3-$ 0.9)] obtained from the Production Area of the Faculty were employed. All the rabbits were humanely euthanized for reasons unrelated to this study.

Vascular injection and dissection. For vascular injection, the abdominal aorta was approached by placing a vascular catheter of 18 G X $11 / 2$ " into the thoracic portion of the aorta. Thirty abdominal aortas were injected with $10 \mathrm{ml}$ of red latex to enhance arterial structures during dissection.

Dissection was performed by approaching abdominal cavity by means of a longitudinal incision over the linea alba. Abdominal organs were reflected to the left side of the abdomen for better visualization of the abdominal aorta.

\footnotetext{
${ }^{1}$ Cuerpo Académico en Ciencia e Innovación Tecnológica Pecuaria, Universidad Autónoma del Estado de México, México.

${ }^{2}$ Cuerpo Académico en Innovación en Anestesiología, Farmacología y Cirugía Aplicada a las Ciencias Médico Veterinarias, Universidad Autónoma del Estado de México, México.

${ }^{3}$ Cuerpo Académico en Comportamiento Bienestar y Sutentabilidad Animal de la Universidad Autónoma del Estado de México, México.

Este trabajo ha sido financiado por la Universidad Autónoma del Estado de México (3712/2014/CID).
} 
Anatomical landmarks to perform the description of the visceral branches of the abdominal aorta were the diaphragm as cranial reference and the external iliac arteries for caudal reference.

Systematic description from cranial to caudal and from right to left side of the abdominal aorta was performed by a double blind method. Position of the visceral branches of the abdominal aorta was recorded to perform schematization of the patterns.

\section{RESULTS}

Vascular injections of red latex allowed to clearly identify the visceral branches arising from the abdominal aorta in the rabbit. Ten different patterns of distribution of the visceral branches arising from the abdominal aorta were identified on this study. All these patterns were schematized for better comprehension of the arterial distribution (Fig. 1). Frequency and relative frequency was obtained for each type of pattern observed in this study.

Type 1. This was found to be the most repeated pattern, 12 of the rabbits $(40 \%)$. Order of appearance was found as it follows: Celiac trunk, cranial mesenteric artery, right renal artery, left renal artery, right testicular artery, left testicular artery and caudal mesenteric artery.

Type 2. This pattern was found in 5 specimens (16.67\%). Variation occurred in the order of the caudal mesenteric artery which was found in a cranial position of both testicular arteries.

Type 3. A total of 3 rabbits have shown this pattern (10\%). The caudal mesenteric artery was found emerging between the right and left testicular arteries.

Type 4. This pattern was demonstrated as a small variation of type 3 pattern. The caudal mesenteric artery arose between the left and the right testicular arteries.

Type 5. In this pattern both testicular arteries were found emerging at the same level from the abdominal aorta and in a caudal position from the caudal mesenteric artery. $6.66 \%$ of the specimens ( 2 rabbits) presented this pattern .

Type 6. The site of origin of the left testicular and caudal mesenteric arteries were found exactly at the same level in two rabbits $(6.66 \%)$ and in a caudal position related to the right testicular artery.
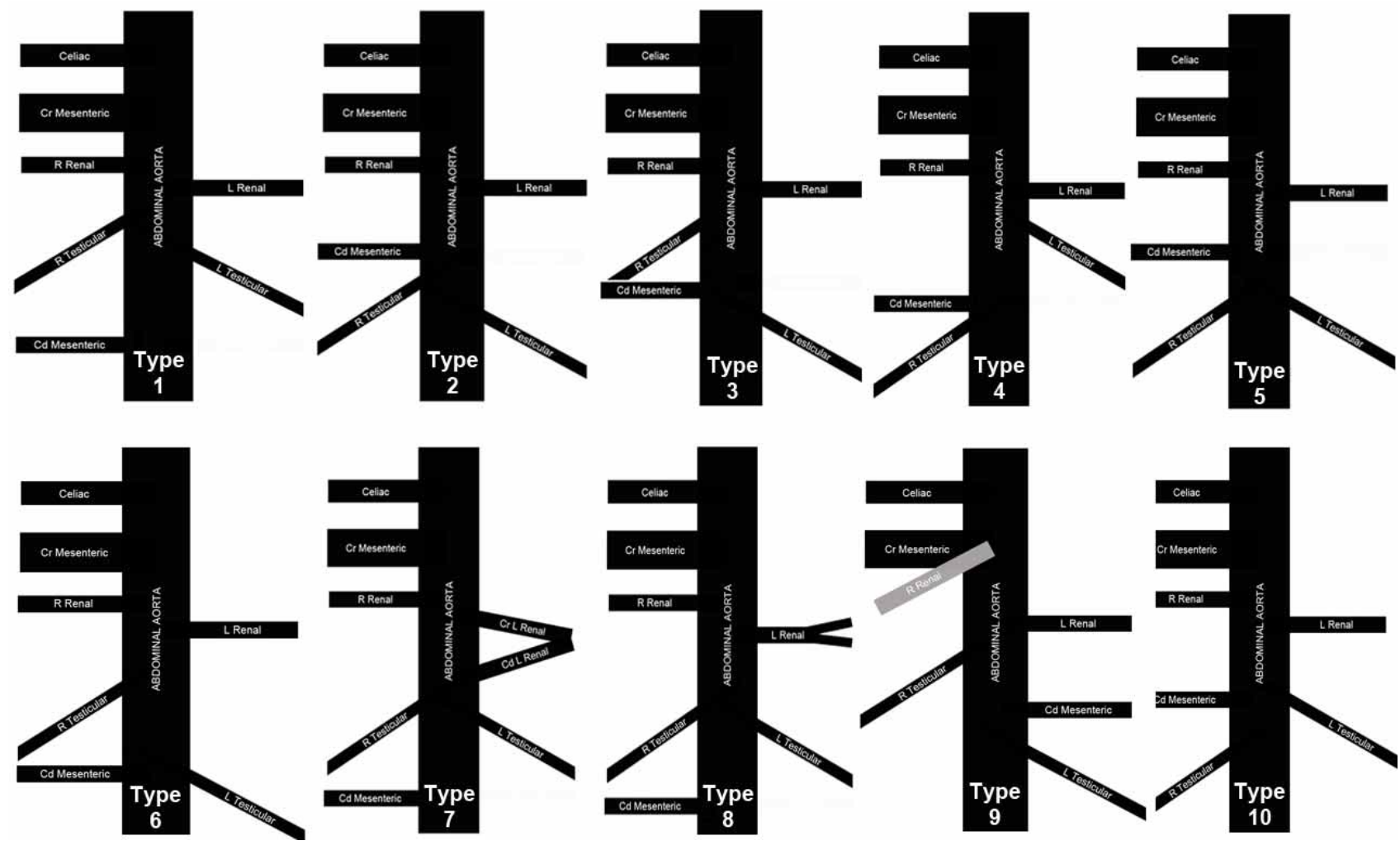

Fig. 1. Aorta. Ten different types of patterns of distribution for visceral branches of the abdominal aorta. 
Type 7. In one specimen (3.33\%) was evident the presence of two left renal arteries, one cranial and one caudal.

Type 8. One specimen (3.33\%) showed the presence of another left renal artery variance, as it was bifurcated before the entrance of the renal hilium.

Type 9. This pattern showed the right renal artery arising at the same level than the cranial mesenteric artery. The origin of the caudal mesenteric artery was located between the right and left testicular arteries. One specimen presented this pattern $(3.33 \%)$.

Type 10. The final pattern featured the origin of the caudal mesenteric and the left testicular arteries emerging at the same level from the abdominal aorta. The right testicular artery arose in a caudal position from these arteries. One specimen showed this pattern.

\section{DISCUSSION}

The abdominal aorta runs over the dorsal abdominal wall in ventral position to the vertebral bodies (Dyce et al.), during its trajectory leaves all the branches for the arterial supply of the abdominal organs (König \& Liebich). All the visceral branches leaving the abdominal aorta were perfectly demonstrated due to the red latex injected in the artery. In all cases of our study, the first visceral branch emerging from the abdominal aorta was the celiac trunk (Nowicki et al.) and the second and third in order of appearance were constantly the cranial mesenteric and the right renal arteries respectively (Getty et al.). However, in one case the cranial mesenteric and the right renal arteries were found emerging at the same level from the aorta.

The left renal artery was always found as the fourth branch emerging from the aorta (Getty et al.; Nowicki et al.; Dyce et al.), nevertheless, two cases showed two major variations of this arterial branch. The first variation case demonstrated the presence of two left renal arteries, one cranial and one caudal, both arising independently from the aorta and introducing separately the renal hilium (Nowicki et al.). The second variation case showed the bifurcation of the left renal artery before it reached the entrance to the renal hilium which had not been mentioned before for this specie. In all cases the renal arteries emerged at different height from the aorta (Nowicki et al.).

Main variations of the arterial pattern occurred in the arrangement of the gonadal and the caudal mesenteric arteries. The right and left gonadal arteries always descended asymmetrically below the left renal artery (Nowicki et al.). The classical description have mentioned the apparition of this arteries as it follows: Right gonadal artery, left gonadal artery and caudal mesenteric artery (Getty et al.; Nowicki et al.; Dyce et al.). In our study we found seven different patterns between this arteries which is new information regarding the pattern of distribution of this visceral branches arising from the aorta for this specie.

Similar to mentioned for other authors, most of the rabbits in our study presented the common pattern for the visceral branches of the abdominal aorta (Getty et al.; Nowicki et al.; Dyce et al.) (Fig. 1A). However this pattern was present in only 12 of the rabbits which represents less percentage $(40 \%)$ than mentioned for other author in similar specie (Nowicki et al.). Thus, anatomical variations of the visceral branches emerging from the aorta may appear and it is important to keep in mind this information for planning new devices, endovascular therapies and surgical approaches.

In conclusion the present study allowed to identify ten different patterns of anatomical variation in the visceral branches of the abdominal aorta in the rabbit and also permitted to demonstrate that vascular changes are frequent. Thus, it is important to keep in mind this anatomical variations to conduct vascular experimental and training protocols with this specie.

ARREDONDO, J.; SAUCEDO, R.; RECILLAS, S.; FAJARDO, V.; CASTELÁN, O.; GONZÁLEZ-RONQUILLO, M. \& HERNÁNDEZ, W. Visceral branches of the abdominal aorta in the New Zealand rabbit: Ten different patterns. Int. J. Morphol., 35(1):306-309, 2017.

RESUMEN: La aorta abdominal del conejo ha sido objeto de estudio e investigación para desarrollar nuevas plataformas de entrenamiento para protocolos diagnósticos y terapéuticos así como para probar las virtudes de materiales y equipos endovasculares, sin embargo, existen muy pocas descripciones en la literatura de las ramas viscerales que emergen de la aorta abdominal en esta especie. Las variaciones anatómicas son eventos de ocurrencia común y por lo tanto deben ser considerados para realizar investigación y ensayos clínicos. El objetivo del presente estudio ha sido describir los diferentes patrones que pueden presentar las ramas viscerales que emergen de la aorta abdominal en el conejo.

PALABRAS CLAVE: Aorta; Inyección vascular; Conejo; Variación anatómica 
ARREDONDO, J.; SAUCEDO, R.; RECILLAS, S.; FAJARDO, V.; CASTELÁN, O.; GONZÁLEZ-RONQUILLO, M. \& HERNÁNDEZ, W. Ramas viscerales de la aorta abdominal en el conejo neozelandés: Diez patrones de presentación. Int. J. Morphol., 35(1):306-309, 2017.

\section{REFERENCES}

Dyce, K. M.; Sack, W. O. \& Wensing, C. J. G. Textbook of Veterinary Anatomy $4^{\text {th }}$ ed. St. Louis, Saunders/Elsevier, 2010.

Fan, J.; Kitajima, S.; Watanabe, T.; Xu, J.; Zhang, J.; Liu, E. \& Chen, Y. E. Rabbit models for the study of human atherosclerosis: from pathophysiological mechanisms to translational medicine. Pharmacol. Ther., 146:104-19, 2015.

Getty, R. Sisson y Grossman Anatomía de los Animales Domésticos. Tomo II. $5^{\text {a }}$ ed. Barcelona, Salvat, 1982.

König, H. E. \& Liebich, H. G. Veterinary Anatomy of Domestic Mammals. Textbook and Colour Atlas. $4^{\text {th }}$ ed. Stuttgart, Schattauer, 2009

Li, Y.; Zhu. Y.; Deng, Y.; Liu, Y.; Mao, Y.; Wang, J. \& Sun, J. The therapeutic effect of bevacizumab on plaque neovascularization in a rabbit model of atherosclerosis during contrast-enhanced ultrasonography. Sci. Rep., 6:30417, 2016

Nowicki, W.; Brudnicki, W.; Iwan czyk, M.; Jabonski, R. \& Skoczylas, B. Variation in branches of the abdominal aoorta in european rabbit. Electro. J. Pol. Agric. Univ., 13(4):10, 2010.

Simgen, A.; Ley, D.; Roth, C.; Cattaneo, G. F.; Mühl-Benninghaus, R.; Müller, A.; Körner, H.; Kim, Y. J.; Scheller, B.; Reith, W. \& Yilmaz, U. Evaluation of occurring complications after flow diverter treatment of elastase-induced aneurysm in rabbits using micro-CT and MRI at 9.4 T. Neuroradiology, 58(10):987-96, 2016.

Yoo, Y. S.; Park, H. S.; Choi, G. H. \& Lee, T. Recent advances in the development of experimental animal models mimicking human aortic aneurysms. Vasc. Specialist Int., 31(1):1-10, 2015.

Zhu, Z.; Han, H.; Zhu, J.; Zhang, J.; Du, R.; Ni, J.; Ying, C.; An, X. \& Zhang, R. Safety and efficacy of a novel iopromide-based paclitaxeleluting balloon following bare metal stent implantation in rabbit aorta abdominalis. Biomed. Mater. Eng., 26(1-2):79-88, 2015.

\author{
Corresponding author: \\ Jorge Arredondo \\ Cuerpo Académico en Ciencia \\ e Innovación Tecnológica Pecuaria \\ Universidad Autónoma del Estado de México \\ MEXICO
}

Email: arredondo.uaemex@gmail.com

Recibido : 30-11-2016

Aceptado: 24-12-2016 